\title{
PARTISIPASI ANGGOTA IKATAN ALUMNI MAGANG JEPANG TERHADAP KELEMBAGAAN PETANI
}

\section{PARTICIPATION OF MEMBERS OF THE JAPAN INTERNSHIP ALUMNI ASSOCIATION IN FARMER INSTITUTIONS}

\author{
Ahmad Syariful Jamil*1, Annisa Fitri ${ }^{2}$, Hidayat ${ }^{1}$, Fadila Marga Saty ${ }^{2}$ \\ ${ }^{1}$ Balai Pelatihan Pertanian Jambi, Jl. Jambi-Palembang Km. 16, Muaro Jambi, Jambi \\ ${ }^{2}$ Prodi Agribisnis Pangan Politeknik Negeri Lampung \\ *E-mail: ahmadsyariful@pertanian.go.id \\ (Diterima 12-04-2021; Disetujui 03-06-2021)
}

\begin{abstract}
ABSTRAK
Kelembagaan petani merupakan tempat berkumpulnya orang-orang untuk menyalurkan kebutuhan aspirasi, pendapat, dan alat untuk pemenuhan kebutuhan pokok. Tujuan penelitian ini adalah menganalisis karakteristik dan partisipasi anggota ikatan alumni magang Jepang terhadap kelembagaan petani. Penelitian ini dilaksanakan dari September 2020 hingga Maret 2021. Responden ditentukan sebanyak 50 orang alumni secara purposive sampling yang tersebar di Provinsi Jawa Barat, Jawa Tengah, dan Jawa Timur. Metode analisis data yang digunakan adalah metode deskriptif kualitatif. Hasil penelitian menunjukkan bahwa karakterisitik anggota ikatan alumni magang Jepang secara umum relatif masih berusia muda, memiliki pendidikan baik formal dan informal yang relatif tinggi, serta sebagian besar usahanya telah berkembang. Keikutsertaan anggota ikatan alumni magang Jepang mengikuti kelembagaan petani sebesar 94\%. Selain itu, sebagian besar alumni Jepang memiliki peran sebagai pengurus dalam kelembagaan petani $68 \%$, dan telah terlibat relatif lama dalam suatu kelembagaan petani. Waktu keterlibatan alumni magang Jepang dalam lembaga pertanian selama lebih dengan masa keterlibatan lebih dari 10 tahun. Salah satu alasan alumni magang Jepang mengikuti kelembagaan petani adalah membantu mendapatkan akses pengetahuan dan teknologi. Hal ini mengindikasikan bahwa alumni memiliki tingkat kesadaran yang tinggi terhadap peran strategis kelembagaan petani dalam memajukan usahanya.
\end{abstract}

Kata kunci: Alumni Magang Jepang, Kelembagaan petani, Partisipasi

\begin{abstract}
Farmer institutions are places where people gather to channel their aspirations, opinions, and tools to fulfill their basic needs. The purpose of this study was to analyze the characteristics and the participation of members of the Japanese internship alumni association to the farmer institution. This research was conducted from September 2020 to March 2021. The respondents were determined as many as 50 alumni by purposive sampling ranging fromWest Java, Central Java to East Java Provinces. The data analysis used was descriptive qualitative method. The results showed that the characteristics of the members of the Japanese internship alumni association in general were relatively young, had relatively high formal and informal education, and most of their businesses had well developed. The participation of members of the Japanese internship alumni association to participate in the farmer institution was $94 \%$. In addition, most of the Japanese alumni had a role as committee members in the farmers institution, 68\%, and had been involved for a relatively long time in the farmer institution. The involvement of alumni in agricultural institutions for more than 10 years. One of the reasons for Japanese internship alumni to join the institution was to help gain access to knowledge and technology. This indicates that alumni had a high level of awareness of the strategic role of farmer institutions in advancing their business.
\end{abstract}

Keywords: Japanese Internship Alumni, Farmer Institutional, Participation 


\section{PENDAHULUAN}

Saat ini perkembangan industri dan teknologi berdampak pada minat budaya untuk bertani semakin rendah. Generasi muda menganggap kehidupan pertanian tidak memiliki prospek jangka panjang. Pola pikir petani menyekolahkan anaknya ke kota untuk menghindari pekerjaan sebagai petani, sehingga generasi muda meninggalkan desanya untuk pergi ke kota dan bekerja pada sektor manufaktur. Hal tersebut berakibat pada alih fungsi lahan pertanian menjadi perumahan di beberapa wilayah pedesaan. Kementerian Pertanian menemukan cara untuk mengatasi permasalahan tersebut dengan memagangkan petani muda dari desa ke Jepang (Gusnelly dan Riskianingrum, 2018).

Pemagangan ke Jepang ini diharapkan adanya peningkatan kualitas sumber daya manusia (SDM) pertanian belajar teknologi pertanian modern yang selanjutnya diharapkan mampu menarik kembali minat generasi muda memasuki sektor pertanian. Penelitian Gusnelly dan Riskianingrum (2018) menyatakan para alumni petani muda IKAMAJA setelah kembali ke desa asal harus menerapkan ilmu pengetahuan yang didapatkan di Jepang. Senada dengan Jamil et al (2021), alumni magang Jepang melakukan wirausaha pertanian di desanya dengan memberikan pengalaman terkait sistem pertanian di Jepang. Transformasi pengetahuan dilakukan dengan cara alumni magang Jepang bergabung dalam kelompok tani dan membantu kelompok tani dalam mendapatkan program bantuan dari pemerintah. Gusnelly dan Riskianingrum (2018) menyatakan bahwa selain bergabung menjadi kelompok tani, para alumni magang Jepang juga melakukan kemitraan dengan perusahaan untuk pemasaran produknya.

Gabungan kelompok tani dan kemitraan merupakan bagian dari kelembagaan petani. Penelitian Fitri et al (2018) dan Isyaturriyadhah et al (2017) menunjukan bahwa faktor yang mempengatuhi petani mengikuti kelompok tani dan kemitraan adalah umur, pendidikan, dan luas lahan. Dengan melakukan kemitraan dapat meningkatkan pendapatan petani karena terdapat jaminan pasar (Fitri et al, 2018). Penelitian Nuryanti et al (2011) menunjukan bahwa dengan bergabung ke kelompok tani merupakan upaya pemberdayaan petani untuk meningkatkan produktivitas, pendapatan, dan kesejahteraan petani. Tidak selamanya kelembagaan petani 
berdampak positif pada petani. Penelitian Duve dan Guveya (2014) menunjukan produktivitas petani rendah, dan penelitian Sari (2012) menunjukan bahwa keuntungan usaha petani yang mengikuti kelembagaan lebih rendah dibandingkan dengan petani yang tidak ikut kelembagaan.

Dengan alumni magang Jepang bergabung dalam kelembagaan petani diduga dapat memberikan pengaruh positif terhadap pembangunan pertanian. Adanya kelembagaan maka terdapat tempat berkumpulnya orang-orang untuk menyalurkan kebutuhan aspirasi, pendapat, dan alat untuk pemenuhan kebutuhan pokok. Berdasarkan permasalahan tersebut perlu dilakukan penelitian karakteristik dan partisipasi anggota ikatan alumni magang Jepang terhadap kelembagaan petani.

\section{METODE PENELITIAN}

Penelitian yang digunakan yaitu pendekatakan kualitatif. Kusuma dan Joka (2020) menyatakan bahwa penelitian kualitatif dikelompokan dalam interpretative inquiry, karena menggunakan faktor subjektif, yang terdiri atas informan, subjek penelitian maupun peneliti itu sendiri. Penelitian ini dilakukan di tiga provinsi, yaitu Jawa
Timur, Jawa Barat dan Jawa Tengah. Penelitian ini dilaksanakan dari bulan September 2020 hingga Maret 2021. Sumber data yang digunakan dalam penelitian ini adalah data primer. Data primer merupakan data yang didapat langsung dari sumber asli (tidak melalui perantara). Metode pengambilan sampel dengan menggunakan purposive sampling sebanyak 50 orang alumni magang Jepang.

Metode analisis data yang digunakan untuk mengetahui partisipasi anggota ikatan alumni magang Jepang terhadap kelembagaan petani adalah metode deskriptif kualitatif. Dalam menganalisis data kualitatif terdapat beberapa tahap yaitu melalui pengumpulan data dan reduksi data. Analisis data pada penelitian kualitatif dapat berupa kata-kata, kalimat-kalimat, atau narasi-narasi baik yang diperoleh dari wawancara mendalam maupun observasi (Kusuma dan Joka, 2020).

\section{HASIL DAN PEMBAHASAN}

\section{Karakteristik Responden}

Responden dalam penelitian ini merupakan alumni peserta program pemagangan petani muda ke Jepang yang berasak dari Provinsi Jawa Barat, Jawa Tengah dan Jawa Timur. Jumlah alumni 
yang menjadi responden sebanyak 50 orang. Karakteristik alumni yang dianalisis meliputi faktor individu dan usaha. Tabel 1 menunjukkan bahwa sebagian besar alumni masih berada di usia produktif, dimana sebesar $56 \%$ responden berada di usia 21 hingga 35 tahun. Dengan rata-rata usia responden sebesar 37 tahun. Selain itu, berdasarkan tahun kepulangan responden didominasi oleh alumni yang relatif baru kembali ke Indonesia. Dimana sebanyak 18 responden yang sudah kembali ke Indonesia kurang dari 5 tahun. Hal ini mengindikasikan bahwa responden umumnya relatif muda dan memiliki retensi yang tinggi terhadap pengalaman magang di Jepang. Alumni yang berusia muda dan memiliki retensi pengetahuan tinggi tentunya akan memiliki kondisi yang lebih prima dibandingkan yang lebih tua. Dengan kata lain, semakin tua usia responden maka makin berkurang kemampuan dalam melakukan kerja.

Tingkat formal dan informal yang dimiliki responden akan menunjukkan tingkat pengetahuan serta wawasan yang luas untuk alumni untuk menerapkan apa yang diperolehnya untuk meningkatkan usahataninya (Mandang, et al 2020). Tabel 1 menunjukkan bahwa tingkat pendidikan yang dimiliki responden paling banyak yaitu tingkat SMA sebanyak $56 \%$ responden, diploma sebanyak $6 \%$, S1 sebanyak $32 \%$ dan S2 sebanyak 6\%. Sementara itu, berdasarkan pendidikan informal (pelatihan) sebagian besar responden telah mengikuti pelatihan sejumlah masing-masing sebesar $60 \%$ kurang dari 5 kali mengikuti pelatihan, 5 sampai 10 pelatihan sebesar $34 \%$, dan sisanya telah mengikuti pelatihan sebanyak lebih dari 10 kali. Tingginya tingkat pendidikan formal dan informal dapat meningkatkan motivasi dalam meningkatkan partisipasi dalam suatu kelembagaan petani.

Selain karakteristik individu, pengalaman usahatani responden merupakan faktor penting dalam meningkatkan tingkat partisipasi pada kelembagaan petani. Anantayu, et.al (2009) menyatakan bahwa pengalaman usahatani mempengaruhi secara tidak langsung efektivitas kelembagaan petani melalui peningkatan kapasitas petani. Pengalaman usahatani dapat menunjukkan seberapa besar seseorang memahami dan mengerti masalah yang ada dalam bidang pekerjaannya (Falo dan Nubatonis, 2017). Rata-rata pengalaman usahatani alumni 5,6 tahun dengan kisaran terbanyak berada antara 1-10 tahun yakni 40 orang dengan persentase 
$80 \%$. Selain itu, sebagian besar atau 47 orang atau $94 \%$ memiliki usaha sampingan. Hal ini menunjukkan bahwa sebagian besar alumni memiliki pengalaman usaha yang cukup baik.

Tabel 1. Karakteristik alumni responden

\begin{tabular}{|c|c|c|}
\hline I. Umur Responden & Frekuensi & $\begin{array}{l}\text { Persent } \\
\text { ase }\end{array}$ \\
\hline $21-35$ tahun & 28 & 56 \\
\hline $41-60$ & 15 & 30 \\
\hline$\geq 61$ & 7 & 14 \\
\hline Total & 35 & 100.00 \\
\hline Rata-rata Umur & 37 tahun & \\
\hline \multicolumn{3}{|l|}{ II. Pendidikan } \\
\hline SMA & 28 & 56 \\
\hline Diploma & 3 & 6 \\
\hline S1 & 16 & 32 \\
\hline S2 & 3 & 6 \\
\hline Total & 50 & 100 \\
\hline \multicolumn{3}{|l|}{ III. Pelatihan } \\
\hline$<5$ kali & 30 & 60 \\
\hline $5-10$ kali & 17 & 34 \\
\hline$>10$ kali & 3 & 6 \\
\hline Total & 50 & \\
\hline \multicolumn{3}{|l|}{$\begin{array}{l}\text { IV. Pengalaman } \\
\text { Usahatani }\end{array}$} \\
\hline $1-5$ tahun & 24 & 48 \\
\hline $6-10$ tahun & 16 & 32 \\
\hline $11-15$ tahun & 3 & 6 \\
\hline $16-20$ tahun & 2 & 4 \\
\hline$>20$ tahun & 5 & 10 \\
\hline Total & 50 & 100 \\
\hline $\begin{array}{l}\text { Rata-rata Pengalaman } \\
\text { Usahatani }\end{array}$ & 5.6 tahun & \\
\hline
\end{tabular}

\section{Partisipasi Anggota Ikatan Alumni Magang Jepang Terhadap Kelembagaan petani}

Pembangunan pertanian mencakup pada pengembangan dan peningkatan kelembagaan. Nasrul (2012) menyatakan pengembangan dan pemberdayaan petani dapat dilakukan melalui kelompok tani, lembaga tenaga kerja, kelembagaan input, kelembagaan output, kelembagaan penyuluh, dan kelembagaan permodalan. Berdasarkan Tabel 2 anggota ikatan alumni magang Jepang mengikuti Kelembagaan petani sebanyak 94\% dan yang tidak mengikuti Kelembagaan petani sebanyak $6 \%$. Keterlibatan alumni magang Jepang dalam posisi kelembagaan sebagai pengurus kelembagaggan sebanyak 34 orang (68\%), posisi alumni magang Jepang sebagai sebagai anggota sebanyak 16 orang (32\%), dan alumni magang Jepang tidak terlibat dalam kepengurusan dan anggota sebanyak 6 orang (12\%). Jangka waktu keterlibatan alumni magang Jepang mengikuti kelembagaan kurang dari 5 tahun sebanyak 11 orang (22\%), 5 tahun sampai dengan 10 tahun sebanyak 16 orang (32\%), dan lebih dari 10 tahun sebayak 23 orang (46\%). Alasan anggota ikatan alumni terlibat dalam Kelembagaan petani adalah mendapat akses pengetahuan atau keterampilan sebesar 40\%, membantu mendapatkan teknologi sebesar 35\%, membatu mendapatkan akses pasar sebesar 20\%, dan mendapatkan akses modal sebesar $5 \%$. Bentuk kelembagaan yang diikuti oleh alumni magang Jepang adalah kelompok tani, Gabungan Kelompok Tani (GAPOKTAN), Ikatan Alumni Magang Jepang (IKAMAJA), dan 
Kontak Tani Nelayan Andalan (KTNA). Pada dasarnya alumni magang Jepang sudah tentu merupakan anggota kelompok tani danatau gabungan kelompok tani. Hal ini dikarenakan keanggotaan dalam Kelembagaan petani merupakan persyaratan alumni sebelum mendaftar menjadi anggota program magang Jepang petani muda. Namun, alumni yang telah Kembali ke Indonesia dan memulai usaha pertanian ada yang keluuar dari kelembagaan tersebut. Salah satu penyebabnya adalah ketidaksesuaian tujuan antar anggota dan pengurus kelembagaan.

Kelembagaan seperti IKAMAJA dan KTNA merupakan kelembagaan yang secara otomatis menampung alumni magang Jepang setelah kembali melaksanakan program Magang di Jepang. Kedua kelembagaan tersebut khususnya KTNA telah memiliki peran strategis dalam pembangunan pertanian nasional (Syahyuti et al, 2014). Namun, peran alumni dalam politik local hingga saat ini belum mengandalkan organisasi formal, melainkan lebih kepada tokoh tertentu. Pada umumnya fungsi advokasi politik baru sebatas peran tokoh-tokoh personal KTNA Padahal KTNA sendiri sudah memiliki fungsi partisipasi dan representasi politik yang strategis. Peran yang dimiliki alumni dalam KTNA seharusnya dapat menjalankan fungsi advokasi dalam rangka meningkatkan kesejahteraan anggota IKAMAJA dan pertanian secara umum. Sehingga tujuan dari adanya program pemagangan tersebut dapat tercapai.

Selain kelembagaan yang memiliki fungsi ekonomi dan politik, terdapat alumni magang Jepang yang mengembangkan kelembagaan pelatihan bagi petani yaitu Pusat Pelatihan Pertanian dan Pedesaan Swadaya (P4S). P4S merupakan Lembaga pelatihan di bidang pertanian pedesaan yang dikelola dan dimiliki petani, baik perorangan maupun kelompok (Yeni et al, 2019). P4S merupakan kelembagaan yang dibina langsung oleh Pusat Pelatihan Pertanian (Puslatan), dan sekaligus yang membina IKAMAJA. P4S yang terbentuk dari, oleh dan untuk petani menekankan pada kemandirian, pemberdayaan dan keswadayaan potensi petani.

Dengan alumni magang Jepang bergabung dalam Kelembagaan petani diharapkan dapat menerapkan inovasi dan kreasi pada kelembagaan dan usaha. Adopsi inovasi nantinya dapat meningkatkan kesejahteraan alumni dan memberikan dampak positif pada lingkungan sekitarnya. Pengalaman yang 
diperoleh selama di Jepang dapat memotivasi alumni untuk dapat meningkatkan kinerja usahanya. Hal ini sejalan dengan penelitian Jamil et al (2021) alumni magang Jepang meningkatkan pendapatan usaha dibandingkan sebelum mengikuti magang Jepang. Kelembagaan petani berfungsi dalam pengelolaan faktor-faktor produksi, proses produksi, dan pengolahan hasil pertanian. Dengan adanya Kelembagaan petani dapt menentukan pengembangan sosial ekonomi petani, seperti aksebilitas inovasi, teknologi, pasar, dan modal. Selain itu, peran organisasi ke depan dalam komunikasi, partisipasi, serta ekonomi dan representasi politik dapat terus ditingkatkan sehingga eksistensinya dapat optimal.

Tabel 2. Partisipasi Anggota Ikatan Alumni Magang Jepang Mengikuti Kelembagaan petani

\begin{tabular}{lr}
\hline \multicolumn{1}{c}{ Uraian } & $\begin{array}{c}\text { Persentase } \\
\text { (\%) }\end{array}$ \\
\hline Keikutsertaan Anggota Ikatan Alumni Magang Jepang Mengikuti Kelembagaan Petani & 94 \\
Ikut dalam kelembagaan & 6 \\
Tidak ikut dalam kelembagaan & 68 \\
Posisi Alumni Magang Jepang dalam Kelembagaan Petani & 32 \\
Pengurus & 12 \\
Anggota & \\
Bukan pengurus dan anggota & 22 \\
Waktu keterlibatan Alumni Magang Jepang dalam Kelembagaan Petani & 32 \\
$<5$ tahun & 46 \\
5 - 10 tahun & \\
$>10 t a h u n$ & 20 \\
Alasan Anggota Ikatan Alumni Magang Jepang Mengikuti Kelembagaan Pertanian & 5 \\
Membantu mendapatkan akses pasar & 40 \\
Membantu mendapatkan akses modal & 35 \\
Membantu mendapatkan akses pengetahuan/keterampilan & \\
Membantu mendapatkan akses teknologi & \\
Sumber: Analisis Data Primer (2021) &
\end{tabular}

\section{KESIMPULAN DAN SARAN}

Karakterisitik anggota ikatan alumni magang Jepang berumur 37 tahun, berpendidikan tingkat SMA sebanyak 56\% responden. Keikutsertaan anggota ikatan alumni magang Jepang mengikuti kelembagaan petani sebesar 94\%. Posisi alumni magang Jepang dalam kelembagaan petani $68 \%$ sebagai pengurus di dalam kelembagaan. Waktu keterlibatan alumni magang Jepang dalam lembaga pertanian selama lebih dari 10 tahun sebanyak 46\%. Alasan alumni magang Jepang mengikuti kelembagaan petani adalah membantu mendapatkan akses pengetahuan dan teknologi. 


\section{UCAPAN TERIMA KASIH}

Penulis mengucapkan terima kasih kepada the Sumitomo Foundation Jepang yang telah memberikan kesempatan dan pendanaan dengan skema Grant for Japan-related Research Projects tahun 2019, sehingga penelitian ini dapat terselesaikan.

\section{DAFTAR PUSTAKA}

Duve, L. D. E. G. (2014). Productivity Analysis of Smallholder OutGrower Tea (Camellia Sinensis) Farming in Chipinge District of Zimbabwe. Journal of Agriculture Economics and Rural Development, 2(4), 128-139.

Falo, M., \& Nubatonis, A. (2017). Partisipasi Anggota Kelompok Tani dalam Berusahatani Bawang Putih di Desa Sallu Kecamatan Miomaffo Barat Kabupaten Timor Tengah Utara. Agrimor, 2(2), 17-22.

Fitri, A., Harianto, H., \& Asmarantaka, R. W. (2018). The Effects of Partnerships on the Efficiency of Mustard Farming at Megamendung District. Jurnal Manajemen Dan Agribisnis, 15(1), 12-22. https://doi.org/10.17358/jma.15.1.1 2

Gusnelly, Riskianingrum, D. (2018). Transfortasi Pengetahuan Alumni Kenshuusei Pertanian Indonesia. Vol. 4.

Isyaturriyadhah, Asnawati Is, E. Y. (2017). Faktor-Faktor Yang Mempengaruhi Partisipasi Anggota Gabungan Kelompok Tani Tanjung Sehati Dalam Kegiatan Kelompok Di Kabupaten Merangin. Prosiding Seminar Nasional Perencanaan Pembangunan Inklusif Desa Kota.

Jamil, A. S., Hidayat, \& Destiarni, R. P.
(2021). ). A Case Study on the Impact of Internship Program towards Farmers Income (the Members of the Japan Internship Alumni Association of East Java). International Journal of Social Science \& Economic Research, 6(3), 1092-1104.

Kusuma. D.L.G., dan U. Joka. 2020. "Analisis Pengelolaan Penjualan Penyambung (Entres) Kopi Berdasarkan Penerapan Social Oriented, Kebun Induk Kopi Robusta, Desa Sai, Kecamatan Pupuan." Agrimor 5(2): 28-31.

Mandang, M., Sondakh, M. F. L., \& Laoh, O. E. H. (2020). Karakteristik Petani Berlahan Sempit di Desa Tolok Kecamatan Tompaso. AgriSosioEkonomi Unsrat, 16(1), 105114.

Nasrul, W. (2012). Pengembangan Kelembagaan petani Untuk Peningkatan Kapasitas Petani Terhadap Pembangunan Pertanian. Menara Ilmu, 29(20), 115-128.

Nuryanti, S. dan D. K. . S. (2011). Peran Kelompok Tani dalam Penerapan Teknologi Pertanian. Forum Penelitian Agro Ekonomi, 29(20).

Sari DP. (2012). Analisis Pendapatan Usaha ternak Ayam Ras Pedaging Pola Kemitraan dan Mandiri di Kecamatan Gunung Sindur Kabupaten Bogor. Institut Pertanian Bogor.

Syahyuti, Wahyuni, S., Suhaeti, R.N., \& Zakaria, A.K. (2014). Arah Kebijakan Pasca Revisi UndangUndang Perlindungan dan Pemberdayaan Petani. Analisis Kebijakan Pertanian, 12(2), 552559.

Yeni, R., Nikmatullah, D., \& Prayitno, R. T. (2019). Peranan Pelatihan Pertanian Pedesaan Swadaya (P4S) dalam Pemberdayaan Petani di Kabupaten Lampung Tengah. JIIA, 7(4), 552-559. 